\title{
Pregnancy-Choosing the Right Anesthesia
}

\author{
Dr. Aloma Wallace, $\mathrm{RN}^{*}$ \\ College of Nursing, Resurrection University, USA
}

*Corresponding author: Aloma Wallace, DNP, MSN, RN, Assistant Professor, College

of Nursing, Resurrection University, USA.

Received Date: July 26, 2019

Published Date: September 25, 2019

\begin{abstract}
Many patients may be encouraged to use an epidural. Attitudes toward epidurals seem routine and similar to a drive through experience. However, the pros and cons need to be addressed, so the mother-to-be can make an informed decision. Some patients suffer some form of trauma, which creates a clot or hematoma, this in turn may affect their lower extremity functioning. Gilman [1] stated that some degree of trauma is usually the cause of a spinal epidural hematoma. Non-traumatic causes include liver disease, anticoagulation therapy, hemophilia, lumbar puncture, aspirin use, and lupus erythematosus. Up to $50 \%$ of the cases of spinal epidural hematoma did not have precipitating trauma or other factors observed. The cases were considered spontaneous (Gilman, 2013) [1].
\end{abstract}

\section{Introduction}

In my research back in 2007, I was amazed by the information that I found, which did not give in to the societal hype of epidurals, but instead made me realize that we need to be sure we educate our patients regarding the possible outcomes, instead of making it sound so trendy. Pamphlets should be given out and pregnant women should be made aware of the possibility of paralysis, especially if they have comorbidities. In this case, my patient had lupus and had experienced paralysis after delivering her child. This 28-yearold female told me she had pregnancy induced paralysis. She was suffering from paraplegia, and was observed to be paralyzed from the waist down. She needed assistance from a homemaker for bathing, diapering, and other needs. I was present to assess her and see how physical therapy could help her regain bilateral lower extremity movement. According to Xiang, Richard [2] though rare, one fatal complication of systemic lupus erythematosus (SLE) is solitary spinal subarachnoid hemorrhage (SAH), with no cranial involvement. Bilateral lower extremity functions usually return after the surgical management of the condition, which involves evacuation of the hemorrhage. The hematoma would be surgically decompressed, and hemostasis achieved [2].

\section{Discussion}

In my own recent pregnancy, my physician discussed a spinal block, but explained the pros and cons, while still allowing me to have an opinion. She encouraged questions and made my husband

and I feel at ease and not rushed. As women, we go in for delivery with prayers and faith, hoping for the best as there is little choice when our procedure has to be done. My spinal went well, but there were hypotensive episodes that left me nauseous and feeling very sick. My anesthesiologist was very professional and communicated with me during my episodes. He acknowledged my condition and assured me the symptoms would subside once my blood pressure was increased.

We have no choice but to trust our healthcare professionals as they carry out the necessary procedures for our care. It is important to be given all the information so an informed decision can be made. My patient, who lived in a lower socioeconomic area did express that she was not advised of these possible outcomes. She may or may not have been given detailed information regarding the extent to which the epidural could affect her with the comorbidities, as it related to her personal outcomes. In her case, she was almost oneyear post op as a paraplegic, with much hope and little bilateral lower extremity function.

\section{Acknowledgement}

None.

\section{Conflict of Interest}

No conflict of interest. 


\section{References}

1. Gilman Larry (2013) Epidural Hematoma Gale Encyclopedia of Nursing and Allied Health.
2. Xiang Yang, Richard SA, Jiagang Liu, Siqing Huang (2018) Systemic lupus erythematosus flare up as acute spinal subarachnoid hemorrhage with bilateral lower limb paralysis. Clin Pract 8(2): 1069. 